\title{
Systematic Screening for Venous Thromboembolic Events in COVID-19 Pneumonia
}

\author{
Gaël Grandmaison ${ }^{1, *}$ Antoine Andrey ${ }^{2, *}$ Daniel Périard ${ }^{3} \quad$ Rolf P. Engelberger $^{3}$ Guillaume Carrel ${ }^{2}$ \\ Sébastien Doll ${ }^{2}$ Jean-Baptiste Dexpert ${ }^{3}$ Caroline Krieger ${ }^{3}$ Hatem Ksouri ${ }^{2}$ Daniel Hayoz ${ }^{1}$ \\ Govind Sridharan ${ }^{2}$
}

1 Internal Medicine, HFR Hôpital Cantonal, Fribourg, Switzerland

2 Intensive Care Unit, HFR Hôpital Cantonal, Fribourg, Switzerland

${ }^{3}$ Angiology Unit, HFR Hôpital Cantonal, Fribourg, Switzerland

TH Open 2020;4:e113-e115.

The new coronavirus disease 2019 (COVID-19) pandemic spreads worldwide, provoking pneumonia, acute respiratory distress syndrome (ARDS) and death. Recently, the medical community has been alerted by reports of coagulation disorders, ${ }^{1,2}$ with arterial and venous thromboembolic events (VTEs) among patients with acute COVID-19. ${ }^{3-9}$ This disproportionate incidence of vascular events seems to be linked to a strong inflammatory response against the severe acute respiratory syndrome coronavirus 2 (SARS-CoV-2), and to an infection of endothelial cells, with endotheliitis, viral inclusions and endothelial cells apoptosis. ${ }^{10,11}$ This systemic endothelial injury, associated with the host inflammatory response against SARS-CoV-2, results in activation of coagulation with arterial, venous, catheter and dialysis filter thromboses. Despite several reports, the incidence of VTEs is not precisely known. As VTE is a treatable condition that may adversely affect the survival of already severely compromised patients, we performed a single cross-sectional systematic search for VTEs among the COVID-19 patients in the intensive care unit (ICU) and medicine ward.

All patients hospitalized in our institution (a 320 beds university hospital) with ARDS or pneumonia, and a SARSCoV-2 positive PCR test, were screened for VTEs on the 7th April 2020. Vascular specialists inspected and performed a complete duplex ultrasound of the neck, of the upper and of the lower limb veins. In case of inconclusive calf veins examination, the latter was repeated within 7 days. Thoracic computed tomography angiography (angio-CT) was performed in case of clinical suspicion of pulmonary embolism (PE) while the duplex ultrasound was negative. Fifty eight patients, 29 in the ICU and 29 in the medicine ward, were screened by duplex ultrasound; 8 of 58 (13.8\%) required a second duplex ultrasound examination of leg veins within 7 days and 16 of 58 (27.5\%) had a thoracic angio-CT performed.

These authors contributed equally to this work.
Address for correspondence Daniel Périard, MD, HFR, Angiology Unit, Hôpital Cantonal, Chemin des Pensionnats 2, 1708 Fribourg, Switzerland (e-mail: daniel.periard@h-fr.ch).

In the ICU, VTEs were found in 17 (58.6\%) of the 29 patients ( - Table 1 ), affecting all investigated sites. Although deep venous thromboses (DVTs) of the calf veins were the most frequent findings (15 patients), internal jugular DVTs and proximal limb DVTs were also found in 5 patients. Two patients had PEs ( 1 intermediate-high risk, and 1 low risk PE). Multi-site VTEs were found in 11 patients. In the ICU, VTEs were found after 6 ( 1 to 15 ) days of ventilation (14 mechanical and 3 non-invasive ventilation), with little or no clinical suspicion. Most VTEs occurred despite thromboprophylaxis with standard dose of low molecular weight or unfractionated heparins. The most significant laboratory findings were high D-dimer levels in VTE-patients, compared with non VTE-patients at time of screening (-Table $\mathbf{1}$ ).

Among the 29 patients hospitalized on the medicine ward who did not require ICU or mechanical ventilation, VTEs were found in 6 (20.7\%) patients: distal DVTs in 6 patients, proximal DTVs in 2 patients, PEs with low risk in 2 patients, multisite VTEs in 4 patients. One patient with multisite VTEs had also an acute arterial thrombosis of the iliac artery, with distal embolization in the foot arch. These events occurred despite anticoagulation for 22 of 29 patients (75.8\%) at prophylactic (55.2\%) or even therapeutic dose (20.7\%).

This survey shows that COVID-19 patients requiring mechanical or non-invasive ventilation are at very high risk of multiple VTEs, despite conventional thromboprophylaxis routinely administered at time of our survey (subcutaneous enoxaprin $40 \mathrm{mg} /$ day or unfractioned heparin 5000 Units twice a day). Applying systematic VTE screening in these patients seems to reveal a much higher incidence than previously reported in observational studies. In line with our report, Llitjos and colleagues found an overall VTE incidence of $69 \%$ in 2 French ICU, where duplex scan ultrasound is performed as a standard of care. ${ }^{12}$ In their multi-centric retrospective study of 388 COVID-19 patients, Lodigiani and colleagues found a VTE incidence of $27.6 \%$ in the ICU, and $6.6 \%$ in the general ward,

(c) 2020 Georg Thieme Verlag KG Stuttgart · New York
License terms

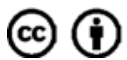


Table 1 Clinical presentation of VTE among the 29 patients with COVID-19 ARDS in the ICU

\begin{tabular}{|c|c|c|c|}
\hline & VTE (17 patients) & No VTE (12 patients) & $p$-value \\
\hline Age $(y)$ & $66(37-79)$ & $65(46-79)$ & NS \\
\hline Male & $64.7 \%(11)$ & $58.3 \%(7)$ & NS \\
\hline \multicolumn{4}{|l|}{ VTE localization } \\
\hline $\mathrm{PE}$ & $11.8 \%(2)$ & & \\
\hline Proximal lower limb DVT & $17.6 \%(3)$ & & \\
\hline Distal lower limb DVT & $88.2 \%(15)$ & & \\
\hline Upper limb/neck DVT & $11.8 \%(2)$ & & \\
\hline Bilateral/multisite & $64.7 \%(11)$ & & \\
\hline Catheter-related & $23.5 \%(4)$ & & \\
\hline BMI & 27 (20 to 34$)$ & 28 (19 to 33$)$ & NS \\
\hline Active cancer & $5.9 \%(1)$ & $8.3 \%(1)$ & NS \\
\hline Previous thrombotic event & $5.9 \%(1)$ & $8.3 \%(1)$ & NS \\
\hline \multicolumn{4}{|c|}{ Duration up to VTE screening (d) } \\
\hline COVID symptoms & $18(11-36)$ & $19(8-28)$ & NS \\
\hline Mechanical ventilation/NIV & $6(1-15)$ & $5(1-16)$ & NS \\
\hline SOFA score & $7(2-14)$ & $8(3-15)$ & NS \\
\hline $\mathrm{PaO2} / \mathrm{FiO} 2$ ratio & $96(59-152)$ & $107(77-239)$ & NS \\
\hline D-dimer $\mu \mathrm{g} / \mathrm{L}$ & $8760(1300-32000)$ & $3150(3100-16100)$ & $<0.01$ \\
\hline $\mathrm{LDH} U / \mathrm{L}$ & $867(498-1785)$ & $695(519-1180)$ & $<0.05$ \\
\hline C-reactive protein mg/L & $306(20-615)$ & $242(170-418)$ & NS \\
\hline Fibrinogen $\mathrm{g} / \mathrm{L}$ & $6.3(1.6-8.0)$ & $6.0(4.0-9.0)$ & NS \\
\hline Platelet count $10^{9} / \mathrm{L}$ & $321(205-522)$ & $359(48-717)$ & NS \\
\hline Ferritin $\mu \mathrm{g} / \mathrm{L}$ & $1228(642-5355)$ & $1834(255-3812)$ & NS \\
\hline \multicolumn{4}{|c|}{ Anticoagulation at VTE diagnosis } \\
\hline None & $11.8 \%(2)^{\mathrm{a}}$ & 0 & NS \\
\hline Prophylactic & $82.3 \%(14)$ & $100 \%(12)$ & NS \\
\hline Therapeutic & $5.9 \%(1)$ & 0 & NS \\
\hline
\end{tabular}

Abbreviations: BMI, body mass index; DVT, deep venous thrombosis; ICU, intensive care unit; NIV, noninvasive ventilation; PE, pulmonary embolism; SOFA, sequential organ failure assessment score; VTE, venous thromboembolic event.

Note: Values are expressed in proportion (and absolute number) and in median and range. Comparison by Wilcoxon ranksum test.

${ }^{a}$ VTE were diagnosed at ICU admission simultaneously to COVID infection.

where VTEs were not systematically searched for. ${ }^{13}$ This difference calls for systematic screening by duplex ultrasound, at regular intervals, for COVID-19 patients. ${ }^{14,15}$ Interestingly, VTEs may affect ambulatory patients or be the reason for hospitalization, since a significant proportion of VTEs were diagnosed within 24 hours of hospital admission in our survey and in the study by Lodigiani and colleagues. ${ }^{13}$

As consequence of our findings, we have adopted the following measures with promising results. In ICU patients, confirmed VTEs were mainly treated either with subcutaneous enoxaparin $1 \mathrm{mg} / \mathrm{kg}$ twice a day or iv continuous unfractioned heparin; and medical ward patients were treated with rivaroxaban at therapeutic doses. Patients were followed by clinical evaluation and repeated duplex ultrasound of the index venous thrombosis. Under therapeutic anticoagulation, we did not observe any extension of thrombosis or new symptomatic event. For those without VTE, the thromboprophylaxis was reinforced to enoxaparin $40 \mathrm{mg}$ twice a day (or 60mg twice a day for $>120 \mathrm{~kg}$ ) in the ICU and enoxaparin $40 \mathrm{mg}$ once a day (or $60 \mathrm{mg}$ once a day for $>80 \mathrm{~kg}$ ) in the medicine ward. During the 4 weeks following the introduction of this new regimen, we observed a dramatic but not complete reduction of new VTE. In conclusion, based on our survey, we believe that VTE should be prevented by reinforced drug thromboprophylaxis. In parallel, intermittent (in the ICU) or permanent (medicine ward) leg compression could be useful if available and not contra-indicated. VTEs should be searched by regular clinical evaluation and imaging, since the reduction of these events may decrease the morbidity of COVID-19 pneumonia, especially in the ICU. In our experience, a routine four limbs and neck compression duplex ultrasound was able to diagnose a large number of otherwise missed VTE without harm to the patients. 


\section{Conflict of Interest \\ None declared.}

\section{References}

1 Tang N, Li D, Wang X, Sun Z. Abnormal coagulation parameters are associated with poor prognosis in patients with novel coronavirus pneumonia. J Thromb Haemost 2020;18(04):844-847

2 Yin S, Huang M, Li D, Tang N. Difference of coagulation features between severe pneumonia induced by SARS-CoV2 and non-SARSCoV2. J Thromb Thrombolysis 2020. Doi: 10.1007/s11239-02002105-8

3 Cui S, Chen S, Li X, Liu S, Wang F. Prevalence of venous thromboembolism in patients with severe novel coronavirus pneumonia. J Thromb Haemost 2020. Doi: 10.1111/jth.14830

4 Klok FA, Kruip MJHA, van der Meer NJM, et al. Incidence of thrombotic complications in critically ill ICU patients with COVID-19. Thromb Res 2020. Doi: 10.1016/j.thromres.2020.04.013

5 Klok FA, Kruip MJHA, van der Meer NJM, et al. Confirmation of the high cumulative incidence of thrombotic complications in critically ill ICU patients with COVID-19: An updated analysis. Thromb Res 2020;S0049-3848(20)30157-2

6 Helms J, Tacquard C, Severac F, et al; CRICS TRIGGERSEP Group. (Clinical Research in Intensive Care and Sepsis Trial Group for Global Evaluation and Research in Sepsis). High risk of thrombosis in patients with severe SARS-CoV-2 infection: a multicenter prospective cohort study. Intensive Care Med 2020;4:1-10
7 Guo T, Fan Y, Chen M, et al. Cardiovascular Implications of Fatal Outcomes of Patients With Coronavirus Disease 2019 (COVID-19). JAMA Cardiol 2020. Doi: 10.1001/jamacardio.2020.1017

8 Middeldorp S, Coppens M, van Haaps TF, et al. Incidence of venous thromboembolism in hospitalized patients with COVID-19.J Thromb Haemost 2020. Doi: $10.1111 /$ jth.14888

9 Mao L, Jin H, Wang M, et al. Neurologic Manifestations of Hospitalized Patients With Coronavirus Disease 2019 in Wuhan, China. JAMA Neurol 2020. Doi: 10.1001/jamaneurol.2020.1127

10 Varga Z, Flammer AJ, Steiger P, et al. Endothelial cell infection and endotheliitis in COVID-19. Lancet 2020;395(10234):1417-1418. Doi: 10.1016/S0140-6736(20)30937-5

11 Connors JM, Levy JH. COVID-19 and its implications for thrombosis and anticoagulation. Blood 2020:blood.2020006000

12 Llitjos JF, Leclerc M, Chochois C, et al. High incidence of venous thromboembolic events in anticoagulated severe COVID-19 patients. J Thromb Haemost 2020. Doi: 10.1111/jth.14869

13 Lodigiani C, Iapichino G, Carenzo L, et al; Humanitas COVID-19 Task Force. Venous and arterial thromboembolic complications in COVID-19 patients admitted to an academic hospital in Milan, Italy. Thromb Res 2020;191:9-14. Doi: 10.1016/j.thromres.2020.04.024

14 Sikachi R, Agrawal A. Whole body point-care ultrasound for COVID-19: a multi-system approach to a multi-system disease. Anaesthesia 2020. Doi: 10.1111/anae.15087

15 Smith MJ, Hayward SA, Innes SM, Miller ASC. Point-of-care lung ultrasound in patients with COVID-19 - a narrative review. Anaesthesia 2020 